This document was prepared in conjunction with work accomplished under Contract No. DE-AC09-96SR18500 with the U. S. Department of Energy.

\title{
DISCLAIMER
}

This report was prepared as an account of work sponsored by an agency of the United States Government. Neither the United States Government nor any agency thereof, nor any of their employees, nor any of their contractors, subcontractors or their employees, makes any warranty, express or implied, or assumes any legal liability or responsibility for the accuracy, completeness, or any third party's use or the results of such use of any information, apparatus, product, or process disclosed, or represents that its use would not infringe privately owned rights. Reference herein to any specific commercial product, process, or service by trade name, trademark, manufacturer, or otherwise, does not necessarily constitute or imply its endorsement, recommendation, or favoring by the United States Government or any agency thereof or its contractors or subcontractors. The views and opinions of authors expressed herein do not necessarily state or reflect those of the United States Government or any agency thereof. 


\section{Dynamic Simulation of Shipping Package Subjected to Torque Load and Sequential Impacts}

by

TSU-TE WU

Westinghouse Savannah River Company

Savannah River Site

Aiken, South Carolina 29808

Additional Authors:

PAUL BLANTON

GLENN ABRAMCZYK

This paper was prepared in connection with work done under the above contract number with the U. S.

Department of Energy. By acceptance of this paper, the publisher and/or recipient acknowledges the U. S. Government's right to retain a nonexclusive, royalty-free license in and to any copyright covering this paper, along with the right to reproduce and to authorize others to reproduce all or part of the copyrighted paper. 
Proceedings of PVP2006-ICPVT-11

2006 ASME Pressure Vessels and Piping Division Conference

July 23-27, 2006, Vancouver, BC, Canada

PVP2006-ICPVT11-93326

\title{
DYNAMIC SIMULATION OF SHIPPING PACKAGE SUBJECTED TO TORQUE LOAD AND SEQUENTIAL IMPACTS
}

\author{
Tsu-te Wu \\ Paul S. Blanton \\ Glenn A. Abramczyk \\ Savannah River National Laboratory \\ Aiken, South Carolina 29803 \\ (803) 725-8201, tsu-te.wu@srnl.doe.gov
}

\begin{abstract}
A numerical technique has been developed to simulate the structural responses of radioactive material packaging components requiring closure-tightening torque to the scenarios of the hypothetical accident conditions (HAC) defined in the Code of Federal Regulations Title 10 part 71 (10CFR 71). A rigorous solution to this type of problem poses a considerable mathematical challenge. Conventional methods for evaluating the residue stresses due to the torque load are either inaccurate or not applicable to dynamic analyses. In addition, the HAC events occur sequentially and the cumulative damage to the package needs to be evaluated. Commonly, individual HAC events are analyzed separately and the cumulative damage is not addressed. As a result, strict compliance of the package with the requirements specified in 10CFR 71 is usually demonstrated by physical testing. The proposed technique utilizes the combination of kinematic constraints, rigid-body motions and structural deformations to overcome some of the difficulties encountered in modeling the effect of cumulative damage in numerical solutions.
\end{abstract}

The analyses demonstrating use of this technique were performed to determine the cumulative damage of torque preload, a 30 -foot drop, a 30-foot dynamic crush and a 40 -inch free fall onto a mild steel pipe.

\section{INTRODUCTION}

Drum type packages are widely used to transport radioactive materials. The top closure of a drum type package is typically bolted to the drum flange. The containment vessel usually also has its closure bolted to the vessel flange. Therefore, the effectiveness of the preload both in the drum and the containment vessel closure bolts generated by the closure-tightening torque is a concern.

The shipping packages for radioactive active materials must meet the criteria for the Hypothetical Accident Conditions (HAC) specified in the Code of Federal Regulations Title 10 part 71 (10 CFR 71). The scenarios of the hypothetical accident conditions that occur sequentially are as follows:

1. The package falls from a bridge to impact a essentially rigid road surface below [10 CFR 71.73 (c)1, 30-ft drop test].

2. The package may be impacted by a 1100-pound fragment from the wreckage above falling 30 feet. [10 CFR 71.73(c)2, crush test for lightweight packages].

3. The package is dropped 40 -inches onto a bar representing the package being 
impaled onto a broken rail spur [10 CFR 71.73(c)3, puncture test].

As a common practice, the structural responses of these events are analyzed individually. Thus, the cumulative damage caused by these sequential events is not accurately accounted.

It is a mathematical challenge to evaluate the combined effect of the residue stresses caused by the torque load and the cumulative damage caused by the sequential dynamic impacts. This paper presents a numerical technique to address this issue. Two cases of analyses were performed for a shipping package designed by Savannah River National Laboratory to demonstrate the applications of the technique. The analytical results were verified with experimental package test data.

\section{ANALYSIS}

The analysis is performed using the finite-element method and the ABAQUS/Explicit computer code, version 6.5 (Reference 1) is selected to perform the computations.

The finite-element model is developed using the MSC/PATRAN computer program (Reference 2).

\section{Finite-Element Model}

Figure 1 shows a cut-away illustration of a 9977 Package. Both the package geometric configuration and applied loads share a plane of symmetry. The finite-element model is of one-half of the package with the symmetry condition applied to the cut-plane.

The finite-element models of the drum's cylindrical body, closure lid and bolt ring, bottom, rim and skirt are comprised of 3D shell elements (Type S4R). 3D solid elements (C3D8R) are used for the foam, the drum bolts and nuts, the containment vessel flange and its closure, fixtures and the contents. The floor, the crush plate and puncture bar are all represented by rigid elements (R3D4). Simulated bolt torque is represented by connector elements.

The preloading conditions in the containment vessel and the drum caused by the closure tightening are first simulated. The analyses then simulate the HAC sequential tests of a 30-foot drop, a 30-foot crush and a 40-inch free fall onto a punch bar. The following two cases with different drop orientations are analyzed.

Case 1: The package is oriented upside down and dropped 30 feet onto a rigid floor. A rigid plate of 1100 pounds then falls from 30 -foot and strikes the bottom of the package. Finally, the package is orientated sideways and is dropped 40 inches onto a rigid long cylindrical bar of 6 inches in diameter. Figure 2 shows the finite-element model for Case 1 analysis.

Case 2: The package is oriented top-down with its axis at a 66-degree oblique angle with respect to the floor and dropped 30 feet onto the rigid floor. In this case, the center of gravity of the package is directly above the corner of the package which first impacts the floor. A rigid plate of 1100 pounds then falls from 30-foot and strikes the bottom corner of the package when the package is in upside-down position. Finally, the package falls 40 inches sideway and impacts a cylindrical rigid bar of 6 inches in diameter. Figure 3 shows the finite-element model for Case 2 analysis.

\section{Analysis for Closure Tightening}

The preload generated by tightening the closure bolts after the torque is removed is a body force instead of a surface force and the resulting stresses are in a self equilibrium state. In the conventional analytical method, the preload is treated as an equivalent thermal load using an appropriate temperature difference in the bolt. However, the thermal load is three dimensional and an accurate equivalent thermal load is difficult to determine.

In the present analyses, the action of tightening threads is simulated using the kinematic constraints implemented by the connector elements. Figures 4 and 5 illustrate the bolted connections of the drum closure and the containment vessel closure, respectively.

Figure 6 shows the finite-element model of the drum bolt region. The process and the result of the bolt tightening is simulated using the connector element with the specified kinematic constraints equivalent to the torque load activation. The thread regions of the bolt and the threaded insert are represented with the rigid bodies, whose reference nodes are used to define the nodes of the connector element as shown in Figure 7.

Figure 8 shows the finite-element model of the containment vessel closure. The application of the torque load is also simulated with a connector element with the specified kinematic constraint equivalent to the result of the torque load. The connector element nodes are defined as the reference nodes of two fictitious rigid surfaces whose meshes are consistent with the top surfaces of the containment vessel nut and flange as shown in Figure 9.

The torque loads for the drum closure and the containment vessel are discussed in Appendix A. These loads are used as the input forces along the local $\mathrm{z}$ axes of the connector elements shown in Figures 7 and 9. The results in the closure connection caused by the torque loads can be represented by closing the 
gaps between the two nodes of each connector elements

. The entire process of closure tightening is simulated by two load steps. In the first load step, the negative forces equivalent to the bolt forces at the nodes " $b$ " along the local $\mathrm{z}$ axes of the connectors with nodes "a" fixed are applied. In the second load step, the axial forces are removed while the velocities of the connector motions are specified as zero so that the two nodes of each connector will remain at the same distance to simulate that the threads remain engaged after the torque load is removed.

The same simulation method applies to both Case 1 and 2 analyses.

The analytical results are the same for both cases. The stress distributions in the closure regions of the drum and the containment vessel are shown in Figures 10 and 11 .

\section{Dynamic Analysis of 30-Foot Drop}

For both cases 1 and 2, the package is first subjected to a 30-foot free drop. After a free fall of 30 feet, the package will be traveling at the following velocity before impacting the target floor.

$$
\begin{aligned}
V_{O} & =\sqrt{2 \times 386.4 \frac{\text { in }}{\sec ^{2}} \times 30 f t \times 12 \frac{i n}{f t}} \\
& =527.454 \frac{\mathrm{in}}{\mathrm{sec}}
\end{aligned}
$$

Determination of Impact Initial Velocity In a conventional dynamic analysis, the initial velocity must be defined in the beginning of the analysis. However, in the present case, the first load step is devoted to the simulation of torque preload. During the duration of applying the preload, the model is kept stationary by fixing the nodes at the bottom of the model. Therefore, the velocity of a free-falling package at the instant when it is about to strike the target floor can not be specified as an initial condition.

To work around the inability of defining the initial velocity, the model is forced to move as a rigid body in accordance with a specified time history of velocities. The analytical procedures are as follows.

(1). The fixed boundary conditions applied at the bottom of the package are completely released so that the stationary model is permitted to move.

(2). At the same time, the velocity of the entire package is specified as the boundary condition, following a smooth function as shown in Figure 12 to establish the initial velocity of the impact. Since the traveling velocities of the package is approximately equal to $0.5 V_{0}$ during the time period from 0 to $\mathrm{t}$ and is equal to $V_{0}$ from to $1.5 \mathrm{t}$, the duration of this velocity history can be determined by the following formula.

$$
\left(0.5 V_{0}\right) \times t+V_{0} \times(0.5 t)=d
$$

or,

$$
t=\frac{d}{V_{0}}
$$

where $t=$ traveling time of package as a rigid body to establish the impact initial velocity.

$d=$ initial distance between the package and the target floor.

$V_{0}=$ initial impact velocity.

The initial impact velocity is established during the same time period when the second load step is applied as discussed in the section for the torque preload.

Impact Analysis After establishing the initial velocity, the model has all the appropriate initial conditions and is ready to impact the rigid floor. The finite-element model of the rigid floor for the 30 -foot drop is fixed during the 30 -foot HAC drop simulation and thus, all six degrees of freedom of its reference node vanish; namely,

$$
U X=U Y=U Z=R X=R Y=R Z=0
$$

where $U X, U Y$ and $U Z$ are the $\mathrm{x}, \mathrm{y}$, and $\mathrm{z}$ translations with respect to the global coordinate system; $R X, R Y$, and $R Z$ are the $\mathrm{x}, \mathrm{y}$, and $\mathrm{z}$ rotations.

Figures 13 and 14 show the deformed shapes of the package after a 30-foot vertical drop for the Case 1 and Case 2 analyses, respectively.

\section{Dynamic Analysis of 30-Foot Crush}

For both Case 1 and Case 2 analyses, after the 30-foot vertical drop, the package is crushed by a rigid plate falling 30 feet. At the end of the free fall, the plate will strike the package at the initial velocity of $527.454 \mathrm{in} / \mathrm{sec}$ as calculated by Equation (1). The methodologies to establish the plate initial velocity and to perform the impact analyses are the same as discussed in the above section for the 30-foot drop analyses.

Figure 15 and 16 show the deformed shapes of the packages after the sequential impacts of a 30-foot drop and a 30-foot crush for Case 1 and Case 2 analyses.

\section{Dynamic Analysis of 40-Inch Punch}

Following a 30-foot vertical drop and a crush by a steel plate falling 30 feet, the package will fall 40 inches in a horizontal orientation onto a long, 6-inch 
diameter bar. The initial velocity is calculated as follows.

$$
\begin{aligned}
& V_{o}=\sqrt{2 \times 386.4 \frac{\mathrm{in}}{\mathrm{sec}^{2}} \times 40 \mathrm{in}} \\
& =175.818 \frac{\mathrm{in}}{\mathrm{sec}}
\end{aligned}
$$

For the Case 1 analysis, the methodologies to establish the initial velocity and to perform the impact analyses are the same as discussed in the above section for the 30 -foot drop analyses. Before the processes of establishing the initial velocity and performing the dynamic analyses take place, we want to remove the interferences on the package deformations from the target floor and the steel plate. This can be easily done by applying the same magnitude of rigid body displacement to both the package and the punch bar along the free-fall direction in punching analysis.

However, for Case 2 analysis, the package motions due to the impact loads of the 30-foot drop and the 30foot crush will cause the rotational and translational motions of the punch bar as illustrated in Figure 17. In order to ensure that the punch-bar impact will take place at the desired position and orientation, a kinetic constraint is specified between a reference node of the bar and a certain node of the drum wall which is closest to the bar and also along the bar axis. The connector element between these two nodes will enforce the kinematic constraints so that the punch bar will move with the package before the package starts to impact the bar.

Figure 18 and 19 show the deformed shapes of the packages after the sequential impacts of a 30-foot drop, a 30-foot crush and a 40-inch punch for Case 1 and Case 2 analyses, respectively.

\section{EXPERIMENTAL VERIFICATION}

A series of HAC tests was conducted using 9977 packages. The results are documented in Reference 3. Figure 20a shows the deformed 9977 package after a 30-foot upside down vertical drop; whereas Figure $20 \mathrm{~b}$ is the analytical result. Figure $21 \mathrm{a}$ is the digital radiograph of the package metallic components after a 30 -foot upside down drop and Figure 21b shows the analytical results of the same components. Figures 22a and 22b are the test result of 30-foot upside down oblique corner drop and the corresponding analytical prediction, respectively. Figure 23a shows the deformed package after a 30-foot upside down oblique corner drop followed by a 30-foot oblique corner crush; whereas Figure 23b is the analytical prediction for the same tests.

The above comparisons for various loading conditions indicate that the analytical predictions agree well with the experiment results.

\section{CONCLUSIONS}

A technique of nonlinear dynamic analysis to predict the cumulative damage of the shipping package subjected to the sequential loading of the closure torque load, the 30 -foot drop, the 30 -foot crush and the 40 -inch bar puncture is presented.

The analytical results are compared with the results of the sequential HAC drop tests of the 9977 package with a bolted closure. The analyses correctly predict the cumulative damages of the package.

\section{REFERENCES}

1. ABAQUS, Inc., ABAQUS/Explicit User's Manual V, Version 6.5.

2. MSC/PATRAN, Version 2003r2, MacNealSchwendler Corp., 2003.

3. Gelder, L. G. and May, C. M.,”9977 General Perpose Fissile Packaging Prototype Testing,” M-TRT-A-00007, Savannah River National Laboratory.

4. Spotts, M. F., "Design of Machine Elements," $6^{\text {th }}$ Edition, Prentice-Hall, Inc.

5. "Safety Analysis Report for Packaging Model 9975,” WSRC-SA-2002-00008, Revision 0, December 2003, Westinghouse Savannah River Company. 


\section{APPENDIX A. CALCULATION OF TORQUE LOAD}

\section{A.1 Torque Required for Tightening Cone Seal Nut}

Torque Required to Produce Preload in Thread

The torque required to produce a given preload in the threads of a bolt-nut assembly is given in the following equation (Reference 4):

$$
T_{1}=F_{i} r_{t}\left(\frac{\cos \theta_{n} \tan \alpha+\mu_{1}}{\cos \theta_{n}-\mu_{1} \tan \alpha}\right)
$$

where $T_{1}=$ Torque required for preload

$$
\begin{aligned}
& F_{i}=\text { Preload } \\
& r_{t}=\text { Pitch radius of thread } \\
& \alpha=\text { Helix angle } \\
& \mu_{1}=\text { Coefficient of thread friction }
\end{aligned}
$$

and the angle $\theta_{n}$ is related to the thread angle and the helix angle by the following equation.

$$
\tan \theta_{n}=\tan \theta \cos \alpha
$$

The thread of the SCV cone seal nut is $6 \frac{1 "}{2}-12 \mathrm{UNF}$ 2A. Thus, the thread angle, $\theta$, the pitch, $p$, and the nominal diameter, $d$, and the pitch diameter, $d_{p}$, of the thread in the cone-seal nut are (Reference 5):

$$
\begin{aligned}
& \theta=\frac{60^{\circ}}{2}=30^{\circ} \\
& p=\frac{1^{\prime \prime}}{12}=0.08333^{\prime \prime} \\
& d=6 \frac{1^{\prime \prime}}{2}=6.5^{\prime \prime} \\
& d_{p}=d-0.6495 p=6.5-0.6495 \times 0.08333 \\
& =6.4459^{\prime \prime}
\end{aligned}
$$

Then, the pitch radius of the thread is

$$
r_{t}=\frac{d_{p}}{2}=\frac{6.4459}{2}=3.223^{\prime \prime}
$$

The helix angle is calculated as follows.

$$
\alpha=\tan ^{-1}\left(\frac{p}{\pi d_{p}}\right)=\tan ^{-1}\left(\frac{0.08333}{\pi \times 6.4459}\right)=0.2358^{\circ}
$$

Substituting the values of $\theta$ and $\alpha$ into Equation (A2 ), we obtain the following value of $\theta_{n}$.

$$
\theta_{n}=\tan ^{-1}[\tan (30) \cos (0.2358)] \approx 30^{\circ}
$$

The coefficient of friction for lubricated threads is 0.15 (Reference 4); namely,

$$
\mu_{1}=0.15
$$

Substituting the values of $r_{t}, \theta_{n}, \alpha$ and $\mu_{1}$ into Equation (A-1) yields the following equation of the torque required for tightening the screw.

$$
T_{1}=0.5719 F_{i}
$$

Torque Required to Overcome Friction on Thrust Base

While the cone-seal nut is being tightened, the coneseal plug remains stationary and the cone-seal nut rotates about the plug. Because of the friction on the interface of the nut and the plug, the preload will produce a resistance to the rotation of the cone-seal nut. The additional torque required to overcome this resistance can be expressed in the following form.

$$
\begin{aligned}
T_{2} & =\frac{\mu_{2} F_{i}}{\pi\left(r_{0}^{2}-r_{i}^{2}\right)} \iint r d A=\frac{\mu_{2} F_{i}}{\pi\left(r_{0}^{2}-r_{i}^{2}\right)} \int_{r_{i}}^{r 0} r^{2} d r \int_{0}^{2 \pi} d \theta \\
& =\frac{2 \mu_{2} F_{i}}{3\left(r_{0}+r_{i}\right)}\left(r_{0}^{2}+r_{0} r_{i}+r_{i}^{2}\right) \quad(\mathrm{A}-5)
\end{aligned}
$$

where $T_{2}=$ Torque required to overcome base interface friction

$\mu_{2}=$ Friction coefficient on the interface

$r_{0}=$ Outer radius of the interface

$r_{i}=$ Inner radius of the interface

The outer and inner diameters of the interface given in Reference 5 are:

$$
\begin{aligned}
& d_{o}=6.0^{\prime \prime} \\
& d_{i}=1.4^{\prime \prime}
\end{aligned}
$$

Thus, the outer and inner radii of the interface are:

$$
\begin{aligned}
& r_{0}=\frac{d_{0}}{2}=\frac{6}{2}=3.0^{\prime \prime} \\
& r_{i}=\frac{d_{i}}{2}=\frac{1.4^{\prime \prime}}{2}=0.7^{\prime \prime}
\end{aligned}
$$

The coefficient of friction for the lubricated interface is 0.15 (Reference 4); namely,

$$
\mu_{2}=0.15
$$


Substituting the values of $\mu_{2}, r_{o}$, and $r_{i}$ into Equation (A-5), we obtain the following equation.

$$
\begin{aligned}
& T_{2}=\frac{2 \times 0.15 \times F_{i}}{3(3.0+0.7)}\left[(3.0)^{2}+3.0 \times 0.7+(0.7)^{2}\right] \\
& =0.3132 F_{i}
\end{aligned}
$$

\section{Calculation of Preload}

The total torque applied at the cone-seal nut to ensure metal-to-metal contact for the cone-seal nut and the cone-seal plug is equal to the sum of $T_{1}$ and $T_{2}$; namely,

$$
T=T_{1}+T_{2} \quad(\mathrm{~A}-7)
$$

The given value of the applied torque is $105 \mathrm{ft}-\mathrm{lb}$ $\pm 4 \%$. Thus, the maximum value of the applied torque is:

$T=105 \mathrm{ft}-\mathrm{lb} \times 1.04 \times 12 \mathrm{in} / \mathrm{ft}=1320.4 \mathrm{in}-\mathrm{lb}$

Substituting the values of $T_{1}, T_{2}$, and $T$ into Equation (A-7) yields the following equation.

$$
1310.4=0.5719 F_{i}+0.3132 F_{i}
$$

Thus, the preload in the thread caused by the applied torque of 1310.4 in-lb is:

$$
F_{i}=1480.511 \mathrm{lbs}
$$

\section{A.2 Torque Required for Tightening Drum Bolts}

The following simplified formula is used to calculate the preload produced by the applied torque (Reference 4).

$$
T=0.2 d F_{i}
$$

where $T=$ Applied torque

$d=$ Major diameter of screw

$F_{i}=$ Bolt preload

For a $\frac{5^{\prime \prime}}{8}-11 \mathrm{UNC}-2 \mathrm{~A}$ bolt and an applied torque of 25 foot-pounds, the bolt preload calculated from Equation (8) is:

$$
F_{i}=2400 \text { pounds }
$$




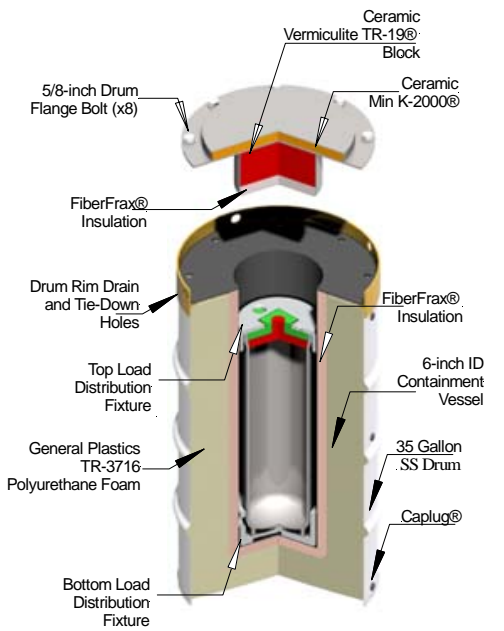

Figure 1. Cut-away of 9977 Package

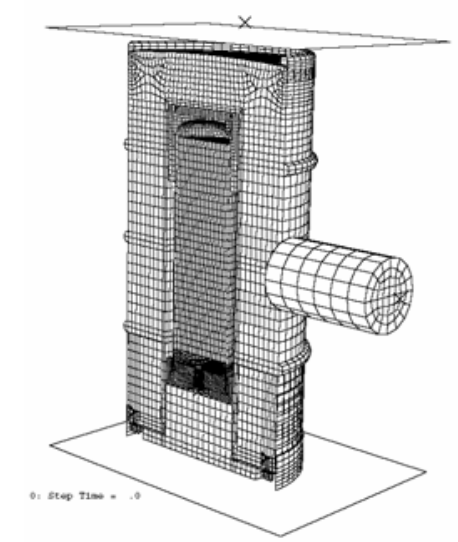

Figure 2. Finite-Element Model for Case 1 Analysis

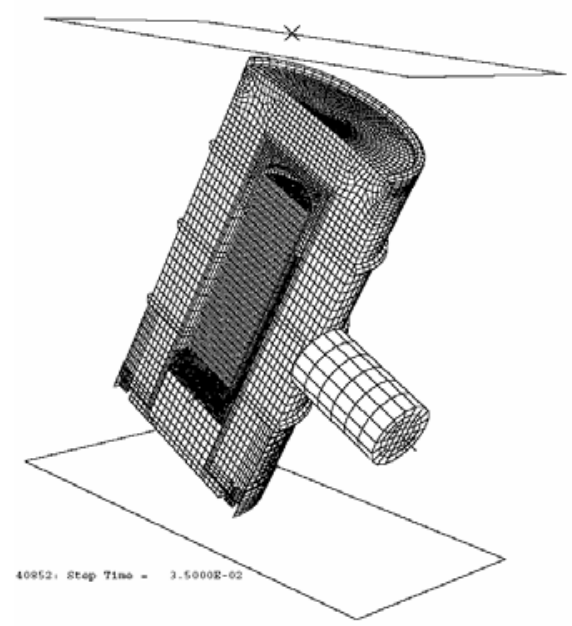

Figure 3. Finite-Element Model for Case 2 Analysis

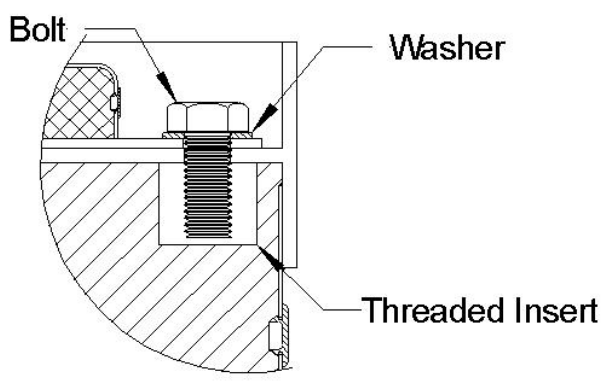

Figure 4. Illustration for Drum Closure Bolts

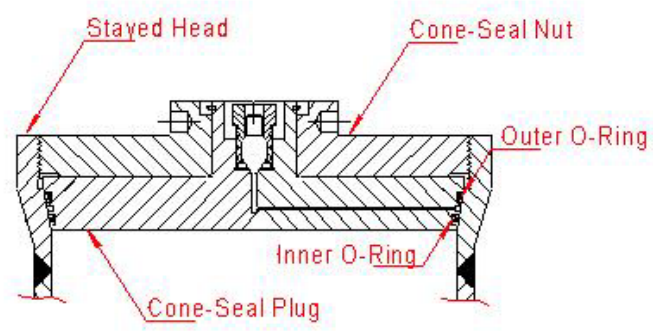

Figure 5. Illustration for Closure of Containment Vessel

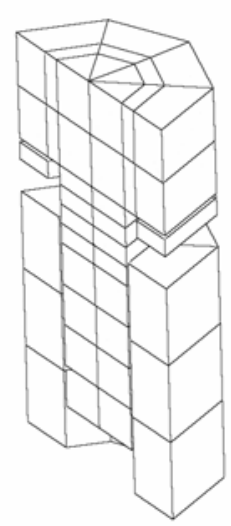

Figure 6. Finite-Element Model of Drum Closure Blot 


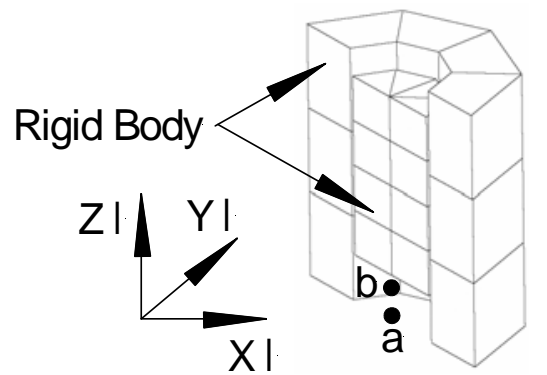

Figure 7.Connector Element for Drum Screw

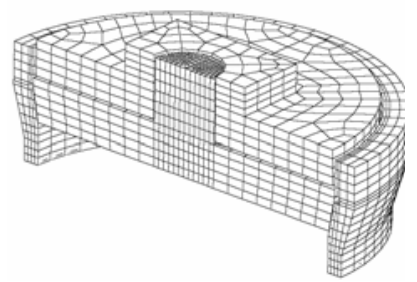

Figure 8. Finite-Element Model of Containment Vessel Closure
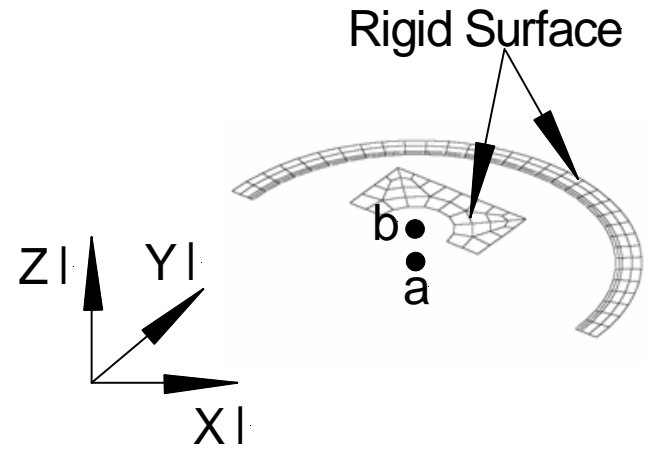

Figure 9. Connector Element for Containment Vessel Closure

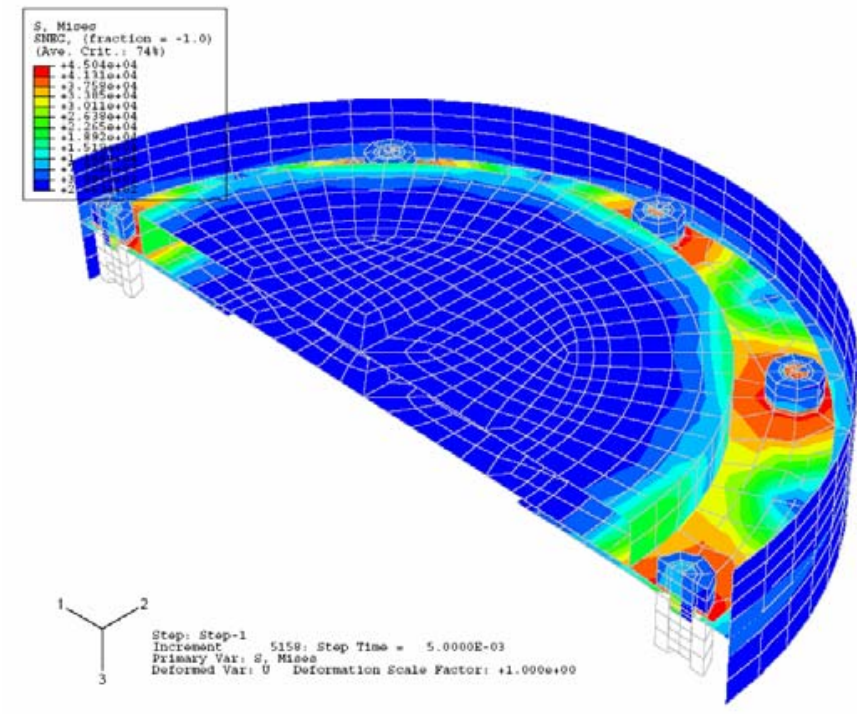

Figure 10. Stress Distribution in Drum Closure after Bolts Tightened

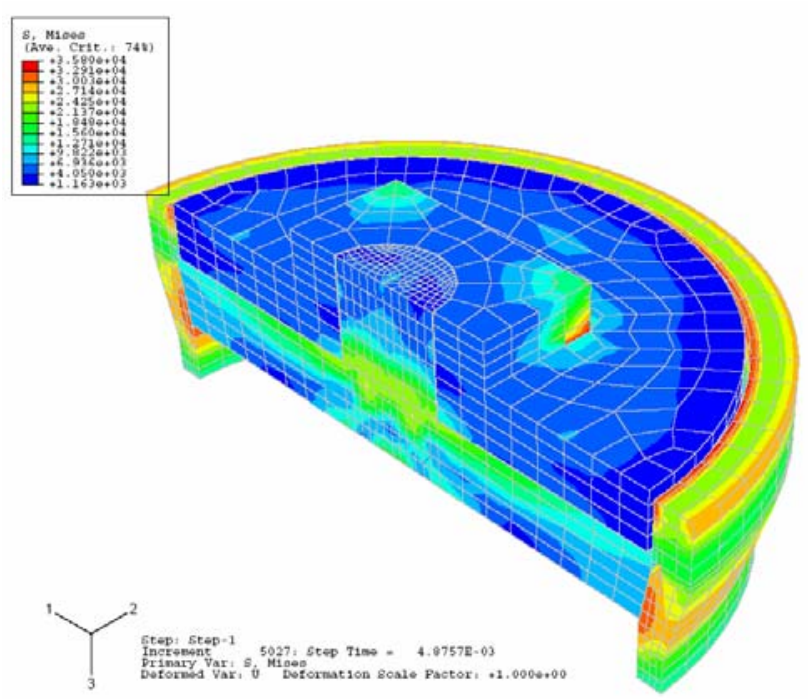

Figure 11. Stress Distribution in Containment Vessel Closure after Plug Tightened 


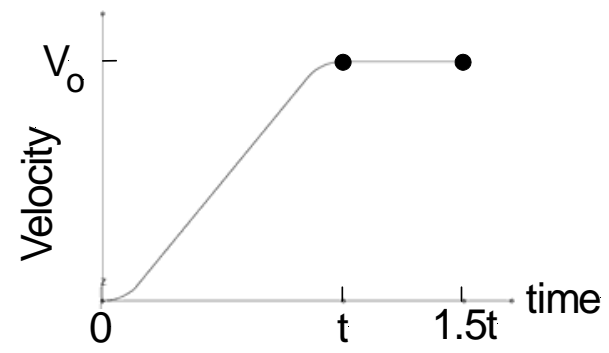

Figure 12. Time History of Package to Establish Impact Initial Velocity

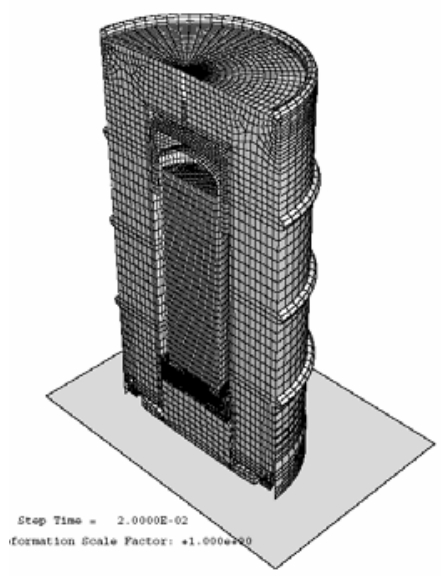

Figure 13. Stress Distribution and Deformed Shape of Package after 30-Foot Drop for Case 1 Analysis

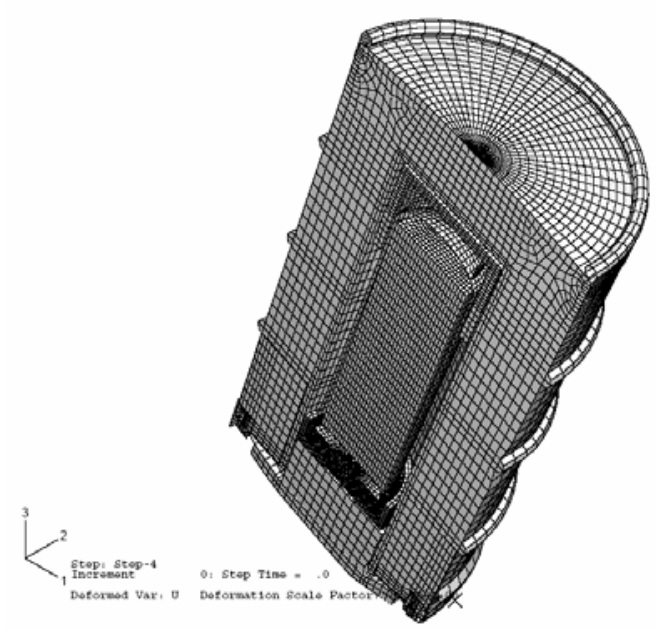

Figure 14. Deformed Shape of Package after 30Foor Drop for Case 2 Analysis

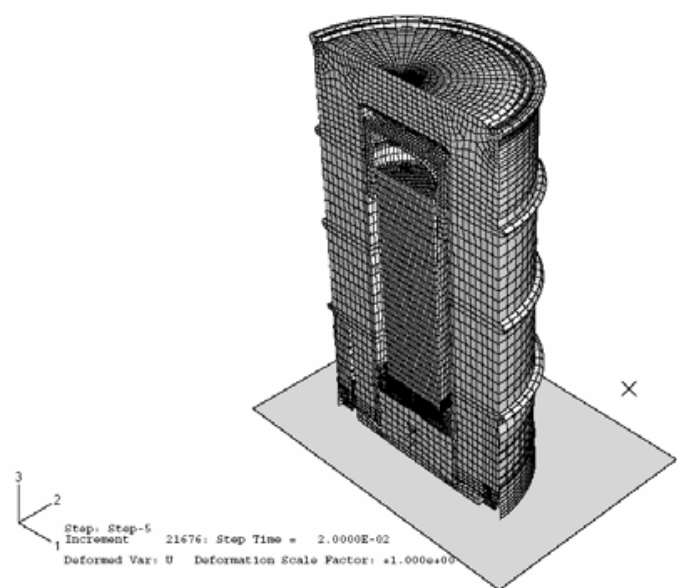

Figure 15. Deformed Shape of Package for the Combined Loads of 30-Foot Drop and Crush (Case 1 Analysis)

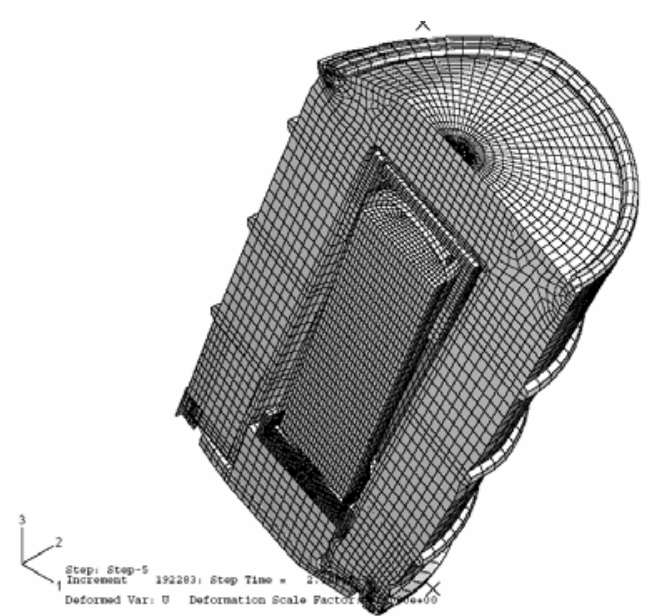

Figure 16. Deformed Shape of Package for the Combined Loads of 30-Foot Drop and Crush (Case 2 Analysis) 


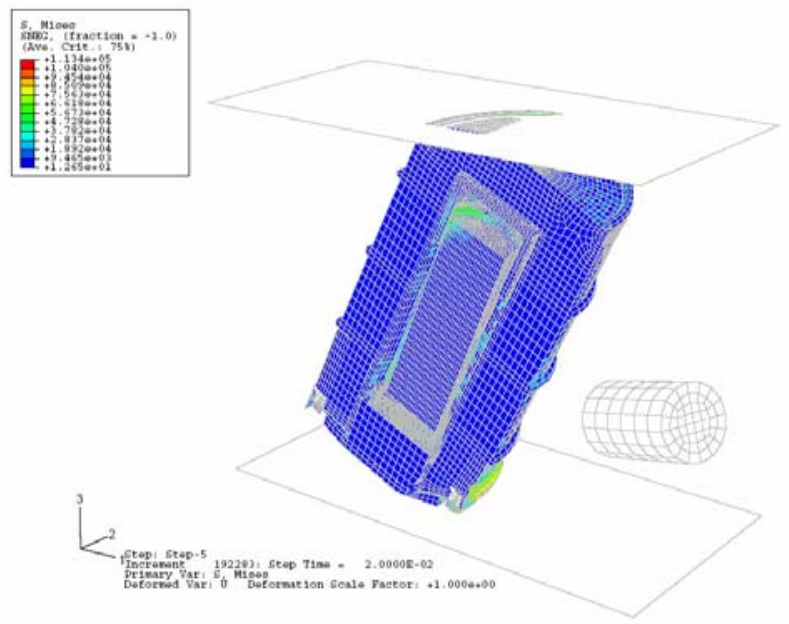

Figure 17. Illustration of Punch Bar Movements Caused by Package Movements

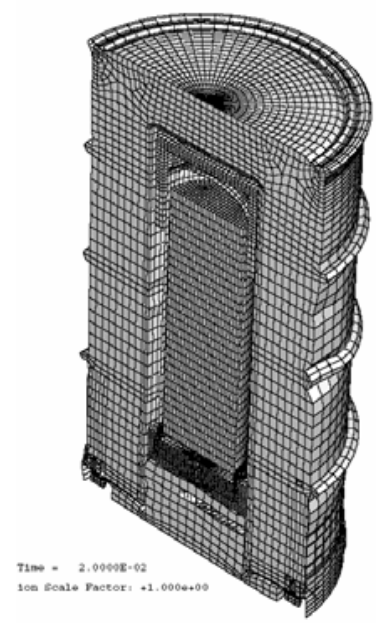

Figure 18. Deformed Shape of Package for the Combined Loads of 30-Foot Drop and Crush and 40-Inch Crush

(Case 1 Analysis)

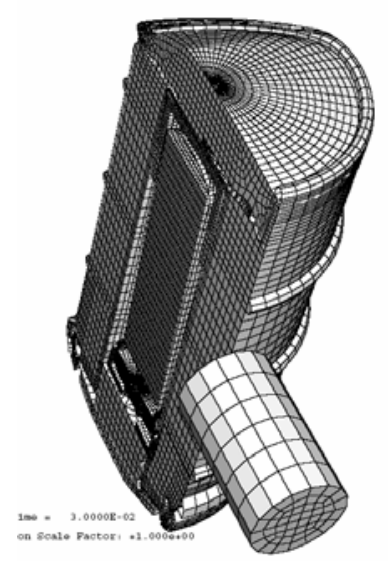

Figure 19. Deformed Shape of Package for the Combined Loads of 30-Foot Drop and Crush and 40-Inch Crush (Case 2 Analysis)

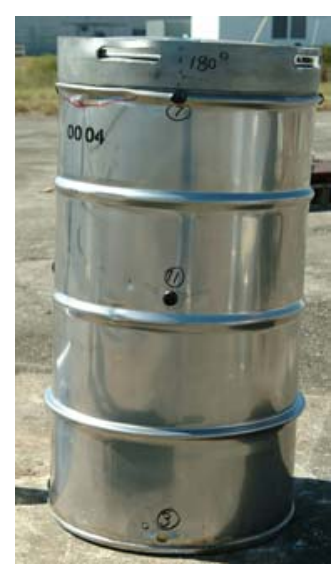

Figure 20a. Test Result of 30-Foot Upside Down Vertical Drop (Case 1 Test) 


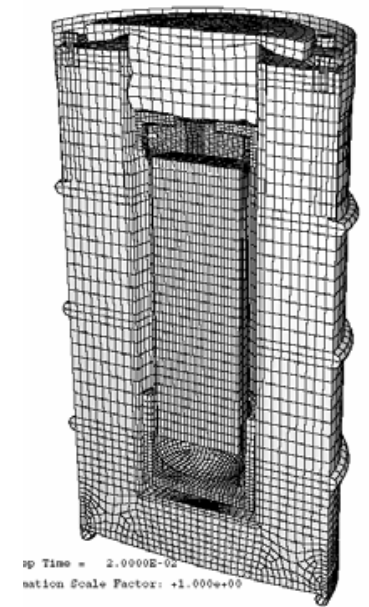

Figure 20b. Analytical Result of 30-Foot Upside Down Vertical Drop (Case 1 Analysis)

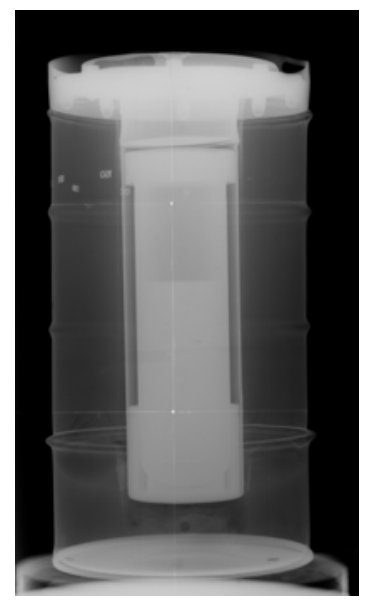

Figure 21a. Radio-Graphic Photo of 30-Foot Upside Down Vertical Drop Test Result (only the metal components are visible) (Case 1 Test)

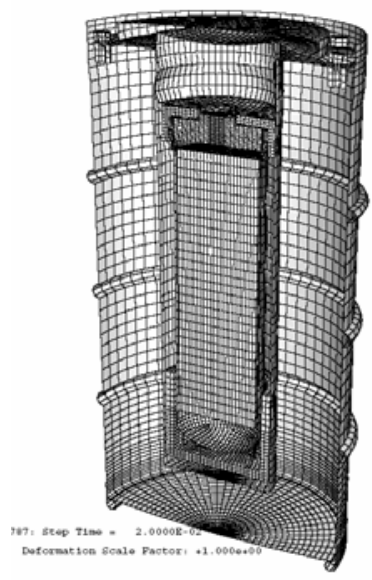

Figure 21b. Analytical Result of 30-Foot Upside Down Vertical Drop (only the metal components are plotted) (Case 1 Analysis)

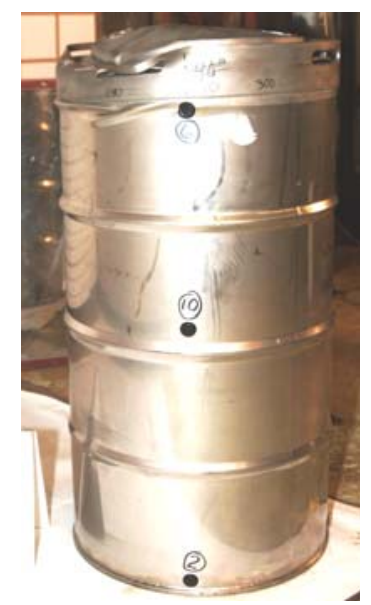

Figure 22a. Test Result of 30-Foot Upside Down Oblique Corner Drop (Case 1 Test) 


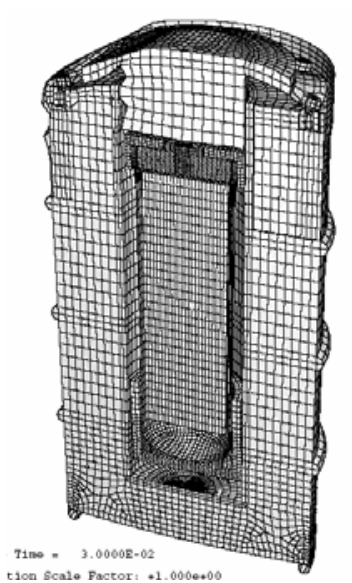

Figure 22b. Analytical Result of 30-Foot Upside Down Oblique Corner Drop (Case 1 Analysis)

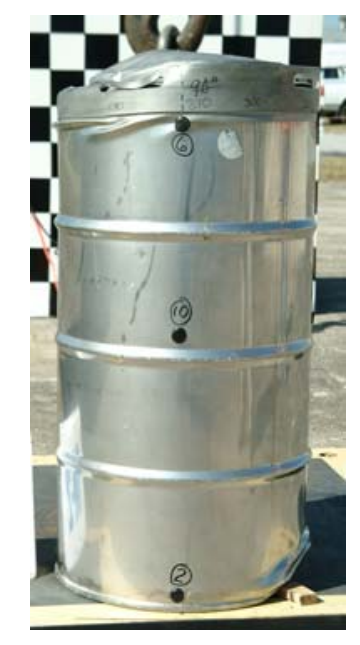

Figure 23a. Test Result of 30-Foot Upside Down Oblique Corner Drop Followed by 30-Foot Oblique Corner Crush (Case 2 Test)

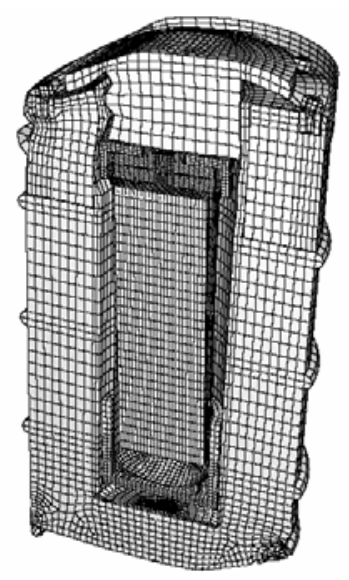

Figure 23b. Analytical Result of 30-Foot Upside Down Oblique Corner Drop Followed by 30-Foot Oblique Corner Crush (Case 2 Analysis) 